\title{
NEUROLOGIA: POSIÇão ACTUAL E PERSPECTIVAS DE FUTURO
}

\author{
Diogo Furtado *
}

O progresso da Medicina, nos últimos 25 anos, pode reputar-se verdadeiramente extraordinário. Sobretudo no campo da terapêutica -- e é êsse precisamente aquêle que mais interessa ao aspecto humano da Medicina - êsse progresso constitui um salto como até hoje se não havia dado na história da Humanidade. A descoberta das sulfamidas e a dos antibióticos criaram uma tal modificação no prognóstico de muitas doenças, uma tal alteração no alcance da terapêutica, que bem podemos dizer que marcaram talvez o mais extraordinário facto do nosso século.

Assistimos à cura de doenças que reputámos, durante anos e anos, incuráveis. Aquêles que, como eu, fizeram o princípio da sua vida num Hospital de moléstias infecto-contagiosas, dificilmente podem conceber como as epidemias da meningite cérebro-espinal deixaram de ser tão mortíferas, para passarem a ser de uma doença quase inofensiva; como as complicações do sarampo e da escarlatina, tão temidas nessa época, desapareceram quase por completo; como o perigo das doenças venéreas se foi esbatendo, a ponto de que o seu significado social se reduziu a infinitamente pequeno.

Assistimos à verdadeira extinção de espécies mórbidas e presenciamos, até, à extinção ou quase extinção de certas especialidades médicas. A venereologia, que há 25 anos constituía a parte mais importante da urologia, quase desapareceu. A gonorréia, doença social há um quarto de século, é hoje uma doença em franca regressão e, em muitos pontos, quase desaparecida. Noutras especialidades o número de doentes reduziu-se imensamente. E' o que vemos, por exemplo, na otorrinolaringologia, onde as complicações supuradas das afecções rino e otogéneas diminuíram numa percentagem extremamente considerável. A própria tuberculose mudou completamente de aspecto. 0 número de sanatórios que, há um quarto de século, era enorme, constituindo uma verdadeira indústria "a latere" da Medicina, começa hoje a declinar. Uma parte importante dêles está em vias de fechar, porque, não só a terapêutica cirúrgica da tuberculose tomou um desenvolvimento extraordinário, como também uma série de me-

Conferência pronunciada na Escola Paulista de Medicina, durante a I Jornada Médica Luso-Brasileira, em 11 setembro 1952.

* Professor da Faculdade de Medicina de Lisboa. Director do Serviço de Neurologia dos Hospitais Civis de Lisboa. 
dicamentos novos. antibióticos ou quimioterápicos, desde a estreptomicina às recenvindas hidrazidas. do ácido nicotínico, mudou completamente a face da doença. E quê dizer do progresso extraordinário da terapêutica psiquiátrica? Psicanálise, insulina, electrochoque e lobotomia transformaram em dinâmica e activa uma psiquiatria estática.

Não foi só na terapêutica, porém, que progrediu a Medicina nestes decênios. Os meios de diagnóstico modificaram-se também. A Física trouxe grande número de aquisições novas; as amplificações electrónicas e os métodos de registro eléctrico permitiram um número considerável de progressos. A desintegração do átomo, a última maravilha da nossa idade, que constitui hoje ao mesmo tempo um terror que assola a humanidade e uma benesse cujas vantagens não sabemos até onde irão, também se re. percutiu na Medicina.

Vimos criar-se uma patologia especial, resultado da aplicação da capacidade explosiva da desintegração atómica, mas vimos ao mesmo tempo surgirem para a ciência, os isótopos e as suas aplicações, quer no diagnóstico quer na terapêutica. Na própria Neurologia começamos a antever a possibilidade de aplicar os isótopos radiactivos no diagnóstico de localização dos tumores do cérebro, proporcionando ao neurocirurgião, pela primeira vez, a possibilidade de, por um método inteiramente inócuo, exterior ao crânio e dispensando qualquer intervenção cirúrgica, presumir com relativo rigor a situação exacta dum tumor cerebral.

Mas não só sob êste aspecto progrediu a Medicina neste quarto de século. Vimos a cirurgia atingir, na última guerra, um elevado desenvolvimento técnico; vimos o desenvolver da anestesiologia, ciência nova que permite ao homem suportar o acto cirúrgico sem qualquer espécie de sofrimento e sem que, ao risco da intervenção cirúrgica, se venham adicionar riscos inerentes às anestesias do passado; vimos surgir uma hemoterapia transfusional altamente desenvolvida, consistindo não só na introdução de sangue e plasma, mas também na de uma quantidade de substitutos cada vez mais perfeitos e cada vez mais úteis.

Assim, o progresso foi materialmente extraordinário. Também, sob o ponto de vista moral, sob o ponto de vista ético e até social, novos problemas vieram encher o espírito dos médicos, trazendo dúvidas que não estão ainda por completo esclarecidas. Veja-se, senão, êsse vasto problema que foi pôsto nos julgamentos de Nuremberg, o da submissão ética do médico aos supostos interêsses do Estado. Os médicos alemães, criminosos de guerra enforcados pelas determinações dêsse tribunal, não eram todos indivíduos de baixo nível cultural dentro da c?asse; alguns dêles eram verdadeiros sábios, com um passado honesto, a cujas consciências foi pôsto o princípio da sua submissão àquilo que os dirigentes do Estado entendiam ser os seus supremos interêsses. Essa submissão conduziu ao que os médicos dos outros países consideraram um crime de guerra, um crime contra a humanidade. Quantas vêzes mais, não serão os médicos 
postos perante circunstâncias semelhantes? Quantas vêzes, talvez a esta hora mesma, noutros países, não estarão médicos submetidos a supostos altos interêsses do Estado, intervindo de maneiras que possam ser consideradas èticamente criminosas?

Até sob o ponto de vista da própria organização da Medicina novos problemas surgiram nestes 25 anos: o maior de todos é o da sua socialização. Em todos os países do mundo, principalmente nos da Europa, se debate neste momento o lancinante problema que a submissão do médico ao Estado, a sua burocratização, trouxe para a classe e até para a ciência médica. Dum lado, os interêsses da comunidade, parecendo exigir que o médico não seja mais do que um empregado do Estado, e portanto um ser assalariado da própria comunidade; por outro lado, os interêsses essencialmente individualistas do médico e até o próprio interêsse da ciência médica, exigindo que o médico não seja um burocrata, um empregado, mas sim um homem livre, cônscio dos seus deveres e das suas responsabilidades, da necessidade de ser útil à sociedade, mantendo independente a sua individualidade.

Vastos prohlemas, vastos progressos!

Mas não foi para tratar dêles que eu vim discorrer, mas sim para, mais modesta e limitadamente, procurar qual foi a posição e evolução da Neurologia, no âmbito dêste progresso imenso.

Em primeiro lugar, existe ou não uma Neurologia? Subsiste ela ou não como especialidade autónoma? Para compreender a extensão dêste problema da actualidade necessário se torna compreender a evolução da Neurologia através da sua história.

A ciência do sistema nervoso constitui, com efeito, um dos ramos mais antigos da Medicina. Já bastante antes de Hipócrates, encontramos menções de estudos que podem ser considerados neurológicos. Assim, e para exemplificar, Empédocles e Anaxágoras ocuparam-se detalhadamente do mecanismo das sensações, estudo que pode ser considerado como um trabalho de fisiologia nervosa.

Em Hipócrates encontramos largas menções às doenças do sistema nervoso. Através daquilo que dêle hoje possuímos e sobretudo dos documentos da colecção hipocrática de Alexandria, verificamos que, para Hipócrates, o cérebro era já o órgão do pensamento. $O$ oráculo de Cós sabia que a sintomatologia das lesões cerebrais era cruzada, conhecia a existência da decussação das vias motoras. Muitas das doenças que hoje individualizamos e tratamos, eram conhecidas do famoso sábio da antigüidade. Assim, êle conhecia a meningite, a apoplexia, e referiu-se largamente à epilepsia, sôbre a qual escreveu páginas fundamentais; sabia até que havia paraplegias, devidas à compressão por gibosidades, que sabemos hoje serem póticas. Também Hipócrates sabia que as cefaléias intensas e continuadas 
eram devidas a hipertensão dentro do crânio, que essas cefaléias podiam conduzir à cegueira, e propunha para o seu tratamento a trepanação descompressiva.

A escola de Alexandria, cêrca de 323 anos anterior a Cristo, teve notáveis investigadores do sistema nervoso. O maior de todos foi talvez Herófilo, o primeiro que estudou a origem dos nervos periféricos, que dissecou até à medula as raízes, estabelecendo o seu ponto de partida medular; foi também Herófilo o primeiro que se referiu aos ventrículos cerebrais e que descreveu os grandes seios venosos da dura-máter e a sua confluência, no ponto que ainda hoje é chamado o lagar de Herófilo. Erasistralo, outro sábio e filósofo da mesma época, distinguia a função intelectual que êle atribuía ao cérebro, da função coordenadora e equilibradora que atribuía ao cerebelo.

Com Galeno novos progressos surgiram. A distinção dos nervos motores e nervos sensitivos, a discriminação das raízes raquidianas foram dados valiosos que Galeno nos deixou. Foi com êle também que surgiu o primeiro trabalho de fisiologia experimental: Galeno verificou, com efeito, que a secção total ou parcial da medula acarretava a paralisia dos membros inferiores; esta foi, talvez, a primeira experiência de fisiologia nervosa de que encontramos menção na história. Foi também Galeno o primeiro que descreveu a epilepsia limitada, a epilepsia focal, aquela a que mais tarde foi dado o nome de "bravais-jacksoniana".

Após êstes grandes homens da antigüidade, a Idade Média trouxe consigo um longo eclipse, dentro do qual os progressos foram insignificantes. Assistimos a discussões de ordem filosófica, sobretudo de base religiosa, mas não vimos progredir a ciência porque a proibição da dissecção dos cadáveres impediu durante séculos êsse progresso. Só no século passado vemos surgir a Neurologia em tôda a sua pujança.

O nascimento da Neurologia, como ciência autónoma, fêz-se quase simultâneamente, em três países distintos, mediante os trabalhos de três escolas, qualquer delas com larga contribuição. A mais importante foi, incontestàvelmente, a Escola Francêsa, da Salpêtrière; com ela nasceu, por assim dizer, o método anátomo-clínico, orientação seguida pelos grandes homens dessa Escola, nomes insignes que começaram com Duchenne de Boulogne, ao qual se seguiu Charcot e, mais tarde, os eminentes discípulos dêste, sobretudo Dejerine, Pierre Marie e Babinski. Os investigadores francêses procuraram, com o seu esclarecido espírito e as suas descrições metódicas, criar quadros clínicos aos quais correspondessem lesões anátomopatológicas perfeitamente definidas e constantemente relacionáveis. E vimos surgir assim um sem número de doenças, que vão da esclerose lateral amiotrófica à esclerose em placas e a tantas outras afecções, aos trabalhos culminantes de Pierre Marie sôbre a acromegália, a afasia, e tantos outros estudos neurológicos, e à obra decisiva de Babinski, estabelecendo uma 
semiologia neurológica valiosa e ainda hoje fundamental para o estudo dos doentes do sistema nervoso.

Ao tempo que isto sucedia em França, desenvolvia-se na Alemanha outra escola neurológica. Pode dizer-se que o primeiro neurólogo alemão foi Romberg que, em 1846, publicou o seu tratado das doenças nervosas; a êle se deve a descrição de um dos quadros fundamentais da patologia nervosa, o do tabes. A seguir, grandes nomes desenvolveram a especialidade, contribuindo decisivamente para o progresso e para o estabelecimento dos direitos de cidade da Neurologia. Entre êles há que citar principalmente Erb que, em Heidelberg, criou uma escola de vasta importância, individualizando sobretudo as doenças dos músculos, criando o electrodiagnóstico e a electroterapia; Friedreich que, em Würzburg, fundou uma escola, e a quem se deve a primeira descrição das heredodegenerescências espino-cerebelosas; Wernicke, o fundador da escola de Breslau, a quem se devem tantos estudos basilares, como êsse da afasia, ao qual o seu nome ficou perpètuamente ligado. Mais tarde surgiram Oppenheim, o grão-mestre da Neurologia alemã, que reuniu numa obra fundamental todos os conhecimentos da sua época, e Foerster, neurólogo eminente, neurocirurgião e sobretudo neurofisiologista e investigador, ao qual se devem as páginas definitivas da Neurologia, que são a sua contribuição para o "Handbuch" de Bumke e Foerster.

Uma terceira escola, inglêsa, evolucionou simultâneamente. Fundada no National Hospital for Paralyzed and Epileptics, de Queen's Square, sendo a mais conservadora de tôdas, foi aquela que manteve, desde a sua fundação até hoje, valor mais constante, e que, neste momento em que as outras se encontram em fase de relativo eclipse, permanece ainda à frente do movimento neurológico mundial. Esta escola, que deve seu impulso ao grande pensador que foi Hughlings Jackson, e a Gowers, outro eminente neurólogo coevo, esta escola, repito, teve sobretudo o valor de proporcionar o ambiente para a criação da neurofisiologia, ligada como está ao nome do maior neurofisiologista de todos os tempos, Sherrington. A Sherrington seguiram-se outros neurofisiologistas eminentes, fazendo da escola neurofisiológica inglêsa a pioneira do movimento mundial. Os clínicos educados neste ambiente de fundamento fisiológico têm sido, até à geração actual, dos maiores que a Neurologia tem produzido; citemos, entre outros, os nomes de Purves-Stewart, Wilson, Cordon Holmes e Russel. Todos êles devem o alto nível atingido, não só ao impulso ideológico fundamental de Hughlings Jackson, mas talvez mais ainda às tendências neurofisiológicas que Sherrington imprimiu definitivamente à Neurologia inglêsa.

Esta fase, em que dominaram as três grandes escolas neurológicas que citamos, é sobretudo caracterizada pelo progresso anátomo-clínico do co. nhecimento do sistema nervoso. A anatomia do sistema nervoso progrediu extraordinàriamente durante esta fase. Não só surgem grandes anatomistas como os clínicos de maior valia mostram grande tendência para o 
estudo da anatomia macro e microscópica do sistema nervoso e para a sua correlação com a clínica.

São conhecidos os progressos que se foram fazendo nos estudos das vias nervosas, partidos das noções de degenerescência de Waller e Bouchard. Ao mesmo tempo, com Flechsig nascia o estudo da mielogênese. Os métodos de coloração desenvolveram-se extraordinàriamente, com as contribuições de Weigert para o estudo da mielina, de Marchi para o estudo da degenerescência mielínica e de Nissl, que nos forneceu um método permitindo corar fácil e rigorosamente as células nervosas. Aqui, há que citar o grande Ramón y Cajal, cujo centenário encontra-se em curso. a quem foi atribuído o prêmio Nobel e que foi, talvez, o maior anatomista do sistema nervoso até hoje existente, criando métodos que permitiram estudar com rigor o aspecto das células nervosas e gliais e dos seus prolongamentos. As impregnações metálicas foram obra sua, e os seus continuadores, como Rio Ortega e Castro, mais não fizeram do que desenvolver os princípios que êle estabelecera. Mas Cajal fêz alguma coisa mais do que ser um anatomista, pois foi um grande filósofo da doutrina neurológica; foi êle quem desenvolveu e criou a doutrina do neurónio, estabelecendo morfològicamente e defendendo a idéia de que a célula nervosa constitui com os seus prolongamentos uma unidade e que entre as diversas células nervosas não há continuidade, mas contigüidade.

Como é sabido, esta doutrina do neurónio encontra-se hoje de novo controversa. Estudos recentes de anatomistas dignos de crédito levan a crer que existe, envolvendo as células nervosas, um plasmódio contínuo, que seria, afinal de contas, a própria negação da doutrina da independência dos neurónios; entretanto, êstes estudos, de Stöhr e de outros, encontram-se em curso e, até hoje, didàcticamente, a doutrina adoptada é a do neurónio. E' possível que ulteriores trabalhos venham mostrar que o sistema nervoso não é descontínuo, mas contínuo. Mas, por ora, devemos manter as afirmações de Cajal até que nos forneçam prova total da sua inexactidão.

A par dêstes grandes anatomistas, não foi menor, como dissemos, o papel dos clínicos anatomistas. Homens como Charcot, Dejerine, Pierre Marie e Gowers deixaram uma obra anatómica absolutamente memorável. Outros mereceriam citação, mas tantos são que é quase impossível fazê-lo. Lembremos van Gehuchten, a quem tanto a neuranatomia deve, e von Monakow, que criou noções novas na anatomia e na fisiologia do sistema nervoso e nos deixou a colecção notabilíssima de que ainda hoje dispõe o Instituto Neurológico de Zurich.

A todos êstes homens se deveram as investigações da fase anátomoclínica da Neurclogia, orientadas principalmente em dois sentidos:

1) O primeiro, o da identificação das lesões típicas para cada nova afecção. Cada quadro clínico que ia sendo descoberto pelos grandes in- 
vestigadores do século passado ia sendo por êles relacionado como lesóes, quanto possível específicas. Estabeleceu-se, dêsse modo, uma verdadeira orientação anátomo-clínica, que até hoje tem gloriosamente persistido.

2) Mas nãci só a pesquisa dos quadros clínicos das afecções nervosas os preocupou como também a pesquisa dos quadros sintomáticos. correspondentes às lesões de determinados pontos do sistema nervoso. Criou-se, assim, uma semiologia correspondente a cada lesão localizada, procurou-se individualizar, para as lesões mínimas dos centros nervosos, os respectivos quadros clínicos. Padrão desta orientação vieram a ser os estudos que conduziram à individualização dos sindromas do istmo do encéfalo, os sindromas do tipo alterno.

O máximo desenvolvimento desta fase anátomo-clínica da Neurologia foi atingido com o estabelecimento duma arquitectura cortical. Depois de Betz, de Campbell, de Brodmann, de von Economo e, por último, dos esposos Vogts, foi possível verificar a existência, no cérebro, de numerosos campos, morfològicamente diferentes. Criou-se, assim, uma verdadeira carta cortical, diferenciada não só sob o ponto de vista da constituição celular das suas diversas camadas, como também sob o ponto de vista mielínico e, até, sob o ponto de vista da sua arquitectura vascular. Apareceram, assim, a cito-arquitectura, a mielo-arquitectura e a ângio-arquitectura do córtex cerebral. Em plena fase localizacionista, não era difícil prever que se procurasse atribuir a cada um dêstes campos uma função. Surgiram então os vários mapas das localizações cerebrais, sobretudo o de Kleist, no qual esta tendência localizadora foi levada ao máximo de diferenciação.

Atingiu-se, pois, com êstes investigadores, o apogeu do método anátomo-clínico.

Vista porém de fora, a posição da Neurologia nãc era de absoluta independência, a despeito de tantos progressos. Podíamos mesmo dizer que a Neurologia não adquirira ainda a sua carta de alforria como especialidade médica. Apareciam tratados de Neurologia, existiam algumas Clínicas Neurológicas, mas em muitos pontos à Neurologia continuava a ser negada a autonomia que almejava. Assim, em certos países víamo-la submetida à clínica médica; encontrávamos, e encontramos ainda hoje, êste fenómeno em Espanha, por exemplo, onde os professores de clínica médica persistem negando a autorização para que a Neurologia possa ter uma existência autónoma. Noutros pontos, vimo-la submetida à Psiquiatria; num país de tão grande desenvolvimento como a Alemanha, as Clínicas de doenças do sistema nervoso continuam a ser sobretudo Clínicas de Psiquiatria.

Ao mesmo tempo, vemos que a própria paragem que se deu na evolução da Neurologia nesta sua fase tornava mais propícia a negação de sua autonomia. Com efeito, por volta de 1930, o método anátomo- 
clínico atingira o seu máximo desenvolvimento. O microscópio e a lupa pouco mais podiam contribuir para o desenvolvimento da Neurologia e esta, limitada a umas quantas entidades anátomo-clínicas, a maior parte das vêzes desprovidas de etiologia, desarmada sob o ponto de vista terapêutico e, ainda por cima, com rudimentares fundamentos fisiológicos, justificava, até certo ponto, que não fôsse por muitos considerada como digna de ter uma autonomia.

E' nesta fase, por volta de 1930 , que vemos surgir um ramo novo da Neurologia, a Neurocirurgia. Não farei em detalhe a história da Neurocirurgia, recentemente escrita por Walker e por Sachs. E' sabido que desde a época neolítica encontramos menção a trepanações, aos crânios de homens neolíticos apresentando vestígios insofismáveis de intervenções cirúrgicas. Na Grécia e em Roma a cirurgia craniana teve certa florescência. Através da Idade Média, as operações sôbre o crânio e sôbre o cérebro limitam-se a muito pouco; em alguns casos raros, encontram-se descritas tentativas de tratamento de lesões cerebrais de homens célebres. E' o caso, por exemplo, do Infante D. Carlos, filho de Felipe II, operado por Vesalio de um abscesso frontal. Raras são as referências a operações cranianas levadas a efeito por cirurgióes ousados (Ambrosio Paré e Berengario de Carpi), e pouco mais, além dessa vaga medieval da operação da "pedra da loucura", que afinal não era mais do que uma intervenção sugestiva destinada a tratar histéricos e psicopatas.

A Neurocirurgia nasceu realmente com Horsley, eminente cirurgião inglês, que praticou, pela primeira vez, intervenções sôbre o sistema nervoso com êxito. Dotado duma técnica prodigiosa, rapidíssimo nos seus actos operatórios, Horsley lutava entretanto com a falta de cuidados pósoperatórios, com a insuficiência da hemostase e da anestesia, que faziam com que os seus resultados fôssem desanimadores.

Pode dizer-se que o caminho para a Neurocirurgia foi aberto pelos trabalhos dos neurofisiologistas. Foi depois que Fritsch e Hitzig, depois que o próprio Horsley e outros demonstraram a possibilidade de cortar no vivo sôbre o cérebro de primatas, que os neurocirurgióes se atreveram a intervenções mais ousadas sôbre o sistema nervoso. Mas, na realidade. a fase moderna e útil da Neurocirurgia nasceu com Harvey Cushing, que havia trabalhado com cirurgióes eminentes como Halstead e Kocher e sobretudo, que havia dedicado parte da sua mocidade ao estudo da neurofisiologia, trabalhando longamente com Sherrington.

Foi Cushing quem deu à Neurocirurgia o relêvo que tem hoje, estabelecendo as técnicas neurocirúrgicas em detalhe, apresentando estatísticas valiosas referentes ao tratamento dos variados tipos de tumores, e tentando a primeira classificação útil dos tumores do sistema nervoso; o trabalho gigantesco de Cushing, que operou milhares de tumores de cérebro, deixando estatísticas ainda hoje valiosíssimas, merece menção especial na história da Neurologia. Contemporâneos de Cushing, Frazier e Elsberg fo- 
ram também eminentes cirurgióes que daquele aproveitaram parte importante do labor e ensinamentos. Walter Dandy, dissidente da escola de Cushing, trouxe também para a Neurologia progressos consideráveis; é a êle que se deve o primeiro método radiológico de diagnóstico dos tumores do cérebro - a ventriculografia - sôbre o qual se baseou em grande parte o progresso da Neurocirurgia e que, ainda hoje, constitui auxiliar precioso dos neurocirurgióes.

Também na Europa a Neurocirurgia se foi desenvolvendo ràpidamente. A par dos grandes neurocirurgióes da primeira fase, os francêses Thierry de Martel e Clovis Vincent, Olivecrona na Suécia, e Foerster na Alemanha, outros foram aparecendo em todos os países. trazendo para a especialidade uma contribuição preciosa. Citemos entre êles os inglêses Jefferson, Cairns e Dott, o suíço Krayenbühl, o alemão Tönnis, o português Almeida Lima.

Uma palavra de saudade para Thierry de Martel que foi o primeiro neurccirurgião francês, grande técnico e homem de espírito que, profundamente patriota e não sabendo sobreviver à derrota da sua pátria, se suicidou quando os alemães entraram em Paris em 1939; outra para Sir Hugh Cairns, grande amigo dos portuguêses, fundador da escola de Oxford, há pouco falecido.

O progresso da Neurocirurgia só foi possível, porém, mercê das aquisições fundamentais que lhe trouxe a neurorradiologia. Falei já na ventriculografia, método de importância basilar, ao qual se deveram as primeiras localizações exactas dos tumores do cérebro. i ventriculografia se seguiram outras variantes, tais como a pneumencefalografia e os seus derivados. Quase ao mesmo tempo, surgiu um método ao qual nós, todos os que usam a língua portuguêsa, devem legítimo orgulho: refiro-me à angiografia.

A descoberta de Egas Moniz, acolhida de início com relativa indiferença, teve dificuldade em abrir caminho na Neurologia, sendo preciso que, na última década, se chegasse ao aperfeiçoamento do método percutâneo para que fôsse reconhecido o real valor da angiografia. Hoje, a angiografia cerebral é um método de tal importância que sobreleva a ventriculografia e domina tôda a neurorradiologia. No diagnóstico das malformações vasculares e dos aneurismas a angiografia é método insuperável e único. Nada que se possa prever, poderá desbancá-lo. No diagnóstico dos tumores constitui contribuição útil, não só para a sua localização, como até para a previsão da sua natureza histopatológica. Aqui, é provável que novos métodos mais inócuos a venham superar; nem por isso, porém, a descoberta de Egas Moniz deixará de ter sido uma das mais valiosas aquisições da Neurologia moderna.

Apoiada, pois, pela neurorradiologia, a Neurocirurgia, na década que vai de 1930 a 1940, parecia dominar completamente a Neurologia. A situação desta aparecia-nos com efeito crítica. $O$ método anátomo-clínico 
atingira os limites das suas possibilidades, e conduzira-a a um esquematismo exagerado. A falta de fundamentos etiológicos forçava a Neurologia a depender da Medicina Interna e dos progressos desta. Por último, a falta de outros recursos terapêuticos fazia sobrevalorizar o papel da terapêutica neurocirúrgica e interessar os neurologistas sobretudo no diagnóstico das afecções com possibilidades de intervenção dêsse género.

Chegara-se, assim, a uma fase em que se previa fàcilmente o desaparecimento da Neurologia. Substituída por um dos seus ramos terapêuti$\cos$ - a Neurocirurgia - absorvida por outro lado pela Medicina Interna e pela Psiquiatria, a Neurologia parecia destinada a desaparecer em breve prazo. Era a época em que Riley, o eminente neurologista de New York, falava de Neurologia irredenta, de fragmentos da Neurologia que se iam irradiando dela e sendo absorvidos por outrem; era a época em que Brower lançava a pergunta sôbre se o neurologista deveria ser um médico ou um cirurgião. O pessimismo acêrca da sorte da Neurologia era, nessa altura, máximo e, diga-se de passagem, justificado.

Ora, de 1940 até hoje a situação modificou-se profundamente. Assistimos a um verdadeiro volte-face, do qual vimos surgir, duma Neurologia moribunda, uma especialidade nova, com mais condições de vida, mais complexa e de maiores perspectivas de futuro. Quais foram então as circunstâncias que desencadearam êste volte-face? A nosso ver, uma circunstância negativa e duas positivas, determinaram esta mudança de atitude.

A circunstância negativa, foi o facto de se terem verificado as limitadas possibilidades da Neurocirurgia. Com efeito, após uma fase de enorme entusiasmo pela cirurgia dos tumores cerebrais, veio-se a constatar que esta tinha recursos relativamente escassos e não impedia, na enorme maioria dessas lesões, o fatal prognóstico que as acompanha. Enveredou a Neurocirurgia, então, por um caminho fisiológico, procurando corrigir defeitos, seccionando vias, anulando centros, dedicando-se, fora do âmbito das neoplasias, a outras afeç̧ões que, até então, não haviam sido consideradas como cirúrgicas. Aqui, o seu progresso tem-se arrastado lentamente, com as dificuldades naturais da qualidade das lesões em causa, mas sem êxitos flagrantes. Assim, o entusiasmo intervencionista neurocirúrgico que caracterizava a fase decorrida entre 1930 e 1940, decaiu sensivelmente, e a Neurocirurgia passou a ocupar, dentro da terapêutica neurológica, o lugar que, lógica e razoàvelmente, lhe competia.

As circunstâncias positivas têm, porém, um interêsse muito maior. Fo. ram elas: uma, por assim dizer de ordem teórica, o ressurgimento de uma velha e esquecida doutrina; outra, de ordem prática, o desenvolvimento extraordinário da neurofisiologia.

Analisemos estas novas circunstâncias decisivas que dictaram a orientação actual da Neurologia.

A doutrina é a de Hughlings Jackson, discípulo do filósofo Spencer e grande clínico nos fins do século passado, que exerceu influência extra- 
ordinária sôbre os clínicos coevos; escreveu êle memoráveis documentos. com raciocínios plenos de inteligência e previsão, sôbre a patologia nervosa, mas seus escritos foram ràpidamente esquecidos e, durante mais de uma vintena de anos, permaneceram num olvido que não mereciam. Foi Pick. talvez, o primeiro que chamou de novo a atenção para o valor da obra de Jackson, e a êste autor muitos outros se seguiram, dando ìs concepções jacksonianas uma actualidade que muito influiu na oriıntação neurológ:ca actual.

São bem conhecidas as idéias de Jackson, para o qual, tal como para Spencer, seu mestre, a organização do sistema nervoso era o resu'tado duma evolução na qual a cada camada se ia sobrepondo outra mais diferenciada. Nas lesões nervosas, Jackson admitia que a lesão causava a destruição dum certo nível e determinava duas ordens de fenómenos: sintomas positivos, resultantes da supressão dêsse nível, conseqüências directas e imediatas da lesão; sintomas negativos, mais importantes ainda do que aquêles, provenientes da liberação das camadas onto e filogènicamente mais inferiores, que estavam inibidas e reguladas por aquela.

Assirn, a concepção jacksoniana trouxe para a Neurologia as noções importantíssimas de níveis e de sintomas negativos, e permitiu explicar muitos fenómenos da patologia nervosa. A sua aplicação atingiu uma cxtensão considerável. A partir de 1930, mais ou menos; surgem traha hos nos quais a doutrina jacksoniana é recordada e aplicada à patologia nervosa. A sua extensão vai mesmo até à psiquiatria; também aqui a noção de níveis de dissolução, de sintomas negativos e positivos, de libertação de funções, adquire uma importância fundamental.

Outros autores trouxeram doutrinas novas que completa:am, até certo ponto, a de Jackson. E' o caso de Goldstein, cujos escritos desempenharam papel muito importante na formação da minha geração neurológica e que, com a sua noção de diferenciação, não fêz mais do que completar o que Jackson considerava como dissolução.

O ponto de vista totalitário de Jackson e de Goldstein, é assumido nos últimos anos por von Weiszäcker, talvez o mais brilhante espírito actual da Neurologia, o qual faz entrar no diagnóstico neurológico uma concepção de totalidade que se não afasta da concepção psicossomática, hoje tão em voga na Medicina Interna de certos países.

Assim, por intermédio da doutrina de Jackson e das doutrinas totalitárias que se lhe seguiram, a Neurologia saiu do esquematismo anátomoclínico em que se encontrava, para um mais vasto horizonte fis:opatológico.

Maior importância ainda teve, talvez, o desenvolvimento da neurofisiologia. Como é sabido, a neurofisiologia nascera com Du Boys Reymond, o primeiro que provocara a excitação do nervo e do músculo por intermédio da corrente eléctrica e tivera em Claude Bernard e Langley 
eminentes investigadores, com os seus estudos fundamentais sôbre o sistema nervoso vegetativo; com Helmholtz nasceram importantes contribuiçōes, quer doutrinárias, como a da conservação da energia ou a da transmissão do influxo nervoso, quer experimentais, como os trabalhos sôbre a audição e sôbre a oftalmoscopia.

Mas pode dizer-se que o verdadeiro advento da neurofisiologia surgiu com Sherrington, o grande fisiologista inglês falecido ainda há bem pouco tempo, que deixou uma obra magistral através da qual, os estudos sôbre a actividade reflexa, sôbre os fenómenos de inibição, de facilitação, de snmação e de inervação recíproca constituem marcos fundamentais. Foi êle o primeiro que, orientado no sentido das idéias de Jackson, falou duma acção integrativa do sistema nervoso e procurou demonstrar experimentalmente a existência de níveis de desintegração. Os seus estudos sôbre as sensibilidades procuravam justamente a diferenciação de um nível epicrítico mais elevado, contraposto ao nível mais baixo de dissolução, o das sensibilidades proprioceptivas.

Head, outro ilustre clínico inglês, contribuiu também eficazmente para a doutrina neurofisiológica, com os seus estudos sôbre a linguagem. A doutrina de Head sôbre a afasia baseia-se nos princípios integrativos jacksonianos, considerando a dissolução afásica constituída por diversos níveis, cada um dêles sobrepondo-se ao seguinte.

A escola russa trouxe também, para o progresso da neurofisiologia, uma contribuição de relèvo. Foi Pavlov, o grande fisiologista de Leningrado, o primeiro que descreveu os reflexos condicionados, provocando-os experimentalmente, e deduzindo da sua experimentação uma vasta teoria filosófica que transformava o sistema nervoso e a actividade humana, esta num conjunto de reflexos condicionados adquiridos ao longo da vida, e aquêle de vias e centros ana!isadores, através dos quais êsses reflexos se faziam. Os sucessores de Pavlov têm produzido trabalho de grande importância e a tão discutida actualmente doutrina de Speransky, que liga tôda a patologia humana com o seu substracto nervoso, não é mais do que uma vasta ampliação das doutrinas que Pavlov trouxe à neurofisiologia.

Outro facto que permitiu o incremento da neurofisiologia foi o advenio das técnicas de registo electrónico. 0 registo do impulso nervoso foi realmente possível, quando os métodos de amplificação electrónica permitiram torná-lo mensurável e ana!isável; aplicado primeiro aos nervos periféricos, êste método de amplificação permitiu que Berger estudasse os ritmos do cérebro humano. A partir da descoberta de Berger, o desenvolvimento da electrencefalografia e o progresso que ela trouxe à neurofisiologia são inestimáveis. Com efeito, ràpidamente se passou do traçado das ondas cerebrais obtidas por electrodos exteriores, à aplicação de electrodos directamente sôbre o córtex cerebral e até à recolha dos impulsos nervosos provenientes de grupos celulares, quer na profundidade do cór- 
tex, quer em órgãos centrais. Ùltimamente, até, o registo eléctrico vai mais longe, permitindo estudar as impulsões nervosas provenientes da própria medula e até de células nervosas isoladas em meios de cultura.

O valor clínico da electrencefalografia é inestimável, quer no diagnóstico da epilepsia, a sua maior coroa de glória, quer no d:agnóstico de localização dos tumores, quer ainda no estudo do sofrimento cersbral por q̨ualquer outra causa. Mas, também, sob o ponto de vista puramente neurofisiológico, um grande número de factos novos veio ao nosso conhecimento, entre os quais avulta a detecção dos circuitos reverberantes, permanentes, que se passam ao nível do sistema nervoso. Novas doutrinas filosóficas foram retiradas da existência dêstes circuitos e essa nova disciplina científica das cibernéticas baseia nos estudos electrencefalográficos principalmente as comparações que faz entre os cérebros electrónicos das máquinas de calcular e o cérebro humano.

O progressc da neurofisiologia continua incessante, mesmo depois do desaparecimento de Sherrington. Vejam-se, por exemplo, êsses dois extraordinários progressos da última década, o estudo das áreas supressoras corticais, por Hines, Dusser de Barenne e Mc Culloch, e o estudo das projecções corticais do feixe piramidal, com a conseqüente dissolução de uniformidade dêste, por Fulton e outros.

Ao mesmo tempo, numerosos outros progressos iam sendo feitos na Neurologia. A extensão da angiografia cerebral não foi das menores; e'a permitiu um estudo, no vivo, da circulação do cérebro com numerosas aportações novas. Também o desenvolvimento da química aplicada ao sistema nervoso trouxe dados importantes. Os estudos histoquímicos e até citoquímicos do tecido nervoso têm feito grandes progressos, permitindo concepções novas. Até a própria aplicação da energia atómica se orienta nestc momento no sentido da Neurologia.

Em tôda a parte se fazem, actualmente, estudos cujo objectivo é a tentativa de localização dos tumores do cérebro por intermédio dos isótopos radiactivos. Com resultados variáveis, extremamente optimistas numas Clínicas, profundamente pessimistas noutras, estas aplicações da detecção da radiactividade no sistema nervoso abrem, entretanto, uma porta nova cujo horizonte não antevemos ainda.

Através de todos êstes progressos e tantos outros como, por exemplo, a aplicação dos métodos genéticos à Neurologia, o progresso nas técnicas de reabilitação física permitindo a recuperação de tantos paraplégicos e defeituosos, etc., a que ponto chegamos neste ano em que vivemos? Qual é, neste momento, a posição da Neurologia e quais são as suas perspectivas futuras?

Assistimos ao ressurgir da Neurologia sob aspecto totalmente diferente. Duma especialidade simplista, essencialmente anátomo-clínica que era 
a Neurologia de nossa aprendizagem, a Neurologia de há duas décadas, chegámos à mais complexa das especialidades actuais.

Jaspers compara o diagnóstico neurológico dos nossos dias com "a combined operation", uma operação combinada, do tipo das operações militares que actualmente caracterizam a guerra: um conjunto muito complexo de infantaria, de aeronáutica, com o apôio aéreo imediato e à distância, de armas pesadas de infantaria e de artilharia, de engenharia e armas espocializadas de todos os tipos, de métodos de deteç̧ão pelo radar, de ataques por armas automáticas à aviação inimiga e de muitos outros sistemas de ataque e de defesa, faz com que a operação militar actual seja. na realidade, um complexo extraordinário que bem merece o nome dado pelos anglo-saxões, de "combined operation".

Ora, a Neurologia é, com efeito, neste momento também "a combined operation". Ela parte duma observação clínica, neurológica, que continua a ser rica de semiótica e exigente de atenção e competência, sôbre a qual enxertam-se métodos radiológicos complexos que vão desde a radiologia simples que em si própria adquiriu grande complexidade, até a angiografia com as suas dificuldades de interpretação e de técnica, aos métodos de contraste gasoso-ventriculografia e pneumencefalografia - nas suas várias modalidades, aos métodos de contraste opaco - - iodoventriculografia, mielografia - e aos métodos de diagnóstico por isótopos radiactivos. A tôda esta complexidade vem somar-se o diagnóstico eléctrico em si, quer o exame eiéctrico dos músculos e dos nervos, a electromiografia, já mais complexa, com as suaj dificuldades de interpretação e a sua técnica delicada, a cronaxia, aquisição importante para o estudo do prognóstico e, por fim, a electrencefalografia e os seus derivados - corticografia, talamografia, eíc. - novo campo indispensável na semiologia neurológica actual. A isto se junta ainda uma complexidade de decisão terapêutica, como talvez nenhuma outra especialidade tenha. Está nesse caso a decisão da intervenção cirúrgica, da sua oportunidade e da sua utilidade, decisão fundamental, a da entrega do doente neurológico ao neurocirurgião.

A terapêutica medicamentosa, que até há pouco era quase nula, com o advento dos antibióticos, sobretudo daqueles que são capazes de actuar sôbre os vírus, tomou complexidade idêntica à do resto da Medicina Interna. Novos métodos terapêuticos foram sendo deduzidos das próprias investigações neurofisiológicas: estão neste caso, as acções sôbre o simpático, os vasodilatadores sôbre os quais longamente temos trabalhado.

A isto se soma, por fim, a indicação fisioterápica, a probabilidade de reabilitação e o método a empregar para ela, e no têrmo, o próprio estudo da neuropatologia que, em relação ao que era há 20 anos, sofreu também um certo desenvolvimento.

Dentro desta complexidade do estudo neurológico vimos renascer uma verdadeira especialidade, a qual tornou mais indispensável o neurologista. 
Este é, com efeito, o chefe desta "combined operation", é aquêle que faz a síntese dos elementos todos que contribuíram para o diagnóstico. que faz a indicação terapêutica, que põe o prognóstico e que, na cúpula de todo êste complexo edifício, congrega os vários elementos para chegar à sua completa utilidade de médico.

Podia dar-vos múltiplos exemplos, como seja o caso do diagnóstico e tratamento da epilepsia, diagnóstico que vai da noção clínica de que determinado ataque mais ou menos frusto ou determinada perturbação paroxística mais ou menos transitória é de natureza epiléptica; depois segue-se o estudo eléctrico do caso, o estudo radiológico e angiográfico; em seguida, a indicação do tratamento médico, hoje duma complexidade enorme exigindo o estudo do doente durante a acção do medicamento, por electrencefalogramas repetidos, por métodos clínicos; por fim, há a possibilidade duma indicação operatória com seus problemas -- técnica desta indicação, estudo corticográfica prévio, prognóstico pós-operatório, estudos dos novos focos epileptógenos que tantas vêzes se formam - $\mathrm{e}$, depois do acto cirúrgico inicial, a indicação de novas intervençōes; tudo isto constitui problema de grande complexidade, uma operação combinada, à qual só o general neurologista pode e deve presidir.

O mesmo se passa, se nos quisermos referir ao estudo dos doentes com rigidez ou com movimentos anormais, ao estudo dos enfermos com dor irreductível, com as indicações cirúrgicas entre as quais está essa nova e extraordinária cirurgia estereotáxica, e até ao estudo dos tumores ou dos ictus apopléticos, cujo diagnóstico é hoje também uma operação combinada, complexa, de dificuldade talvez inigualável em qualquer outro capítulo da Medicina.

Existe um maior equilíbrio hoje entre os diversos sectores da Neurologia, continuando, porém, a clínica à frente dêles. Desapareceu o perigo duma neurocirurgia que cobriria tôda a Neurologia, embora, evidentemente, continue persistindo o interêsse pelos problemas com solução cirúrgica. Mas é o neurologista que continua chefiando e estando na base da operação combinada da Neurologia. Tal como a infantaria continua sendo o fundamento da operação combinada da guerra, a semiótica neurológica é a infantaria da combinada operação da Neurologia, e o neurologista continua sendo o general dessa operação.

Conseqüência prática e imediata desta orientação nova é o que vemos na evolução dos Serviços de Neurologia. Já Brower, em Amsterdam, no Serviço que hoje dirige van Biemond, criara uma unidade complexa, na qual, sob a chefia da Neurologia, procurava juntar as várias subespecialidades que hoje a acompanham. $O$ mesmo se tende a fazer nas Clínicas mais modernas. Nós próprios, no nosso modesto Serviço de Lisboa, seguimos esta orientação: sob uma chefia neurológica e assentando numa base essencial neurológica, procurámos congregar a Neurocirurgia, a Electrencefalografia, a Fisioterapia, os métodos de reabilitação, tôdas as tera- 
pêuticas modernas, a neuropatologia - tudo no mesmo bloco cuja direcção é exclusivamente neurológica.

Podemos pois terminar de novo na apologia da Neurologia. Não estamos já em presença de uma especialidade moribunda, mas novamente na frente de uma especialidade forte, pujante do futuro. Não é já a Neurologia despojada e parente pobre, a Neurologia irredenta de 1930, mas uma especialidade que, por ter adquirido novas, complexas e próprias técnicas de exame, se apresenta como um novo tipo de síntese médica. Uma especialidade mais atraente do que qualquer outra porque junta ao espiritual o orgânico, porque admitindo concepções teóricas, lhes procura dar, cada vez mais, uma base anatómica e fisiológica. Uma especialidade, enfim, que ocupa êsse ponto crucial em que as relações do sistema nervoso com a psique, do cérebro com o espírito, põem ao homem angustiado o magno problema do seu corpo efêmero e da sua alma eterna!

Ar. ('csal Rileiro, 12 - Lisboa - Portugal. 